\title{
Effect of postoperative urinary retention in older patients with hip fracture on self-efficacy, resilience, and quality of life
}

\author{
Yan Tang ${ }^{1 \#}$, Xiao-Yan $\mathrm{Wu}^{2 \#}, \mathrm{Li}-J u n$ Tang ${ }^{2}, \mathrm{Na} \mathrm{Xu}^{1}$, Ying-Jie $\mathrm{Ni}^{1}$ \\ ${ }^{1}$ Department of Orthopedics, Xishan People's Hospital of Wuxi City, Wuxi, China; ${ }^{2}$ Department of Rehabilitation Medicine, Xishan People's \\ Hospital of Wuxi City, Wuxi, China \\ Contributions: (I) Conception and design: All authors; (II) Administrative support: YJ Ni; (III) Provision of study materials or patients: Y Tang, XY \\ Wu; (IV) Collection and assembly of data: All authors; (V) Data analysis and interpretation: All authors; (VI) Manuscript writing: All authors; (VII) \\ Final approval of manuscript: All authors. \\ "These authors contributed equally to this work. \\ Correspondence to: Ying-Jie Ni. Department of Orthopedics, Xishan People's Hospital, 1128 Dacheng Road, Anzhen Street, Wuxi 214000 , China. \\ Email: wx05301025@163.com.
}

Backgroundk Hip fracture (HF) is a major health problem for older patients. Postoperative urinary retention (POUR) is a common complication in HF patients. It extends the length of the hospital stay and affects the recovery of mobility. This study aims to explore the relationship between self-efficacy, resilience, and quality of life in older patients with $\mathrm{HF}$ after HF combined with POUR and to improve the rehabilitation plan for $\mathrm{HF}$ patients.

Methods: A retrospective case-control study was conducted to assess 221 older patients with HF who underwent surgery for the first time at the Department of Orthopedics, Xishan People's Hospital from June 2018 to June 2021. Of these, 111 patients were in the POUR group (Group A), and the remaining 110 patients were in the non-POUR group (Group B). Three months after the operation, a questionnaire was administered to assess the relationship between POUR and self-efficacy, resilience, and quality of life.

Results: Self-efficacy scores of Group A $(23.52 \pm 3.18)$ were lower than those of Group B $(27.23 \pm 2.40)$, and the difference was statistically significant $(\mathrm{P}<0.05)$. Except for self-improvement, subscores and total scores of all resilience measures in Group A were lower than those of Group B, and these differences were statistically significant $(\mathrm{P}<0.05)$. The scores of all quality of life measures of Group A were lower than those of Group B, and the differences were statistically significant except for role-emotional $(\mathrm{RE})(\mathrm{P}<0.05)$. The correlation analysis between self-efficacy and resilience in older patients with HF after the operation showed that self-efficacy was positively correlated with the total resilience score and the toughness optimism dimensions $(\mathrm{P}<0.01)$. Correlation analysis between self-efficacy and quality of life showed that self-efficacy was positively correlated with role-physical (RP), bodily pain (BP), general health (GH), vitality (VT), and social functioning $(\mathrm{SF})(\mathrm{P}<0.01)$. Correlation analysis between resilience and quality of life showed that total resilience scores, toughness, and optimism were positively correlated with physical functioning $(\mathrm{PF}), \mathrm{RP}, \mathrm{BP}$, GH, VT, and SF $(\mathrm{P}<0.05)$.

Conclusions: The combination of POUR after HF significantly reduces self-efficacy, resilience, and quality of life in older adults.

Keywords! Older adults; hip fracture (HF); postoperative urinary retention (POUR); self-efficacy; quality of life

Submitted Aug 13, 2021. Accepted for publication Oct 12, 2021.

doi: 10.21037/apm-21-2556

View this article at: https://dx.doi.org/10.21037/apm-21-2556 


\section{Introduction}

Older adults are prone to fractures after falls due to severe osteoporosis, among which hip fractures (HFs) are the most common. HF refers to a fracture that occurs between the femoral neck and the femoral trochanter. With the increase in the global older adult population, the incidence of $\mathrm{HF}$ is expected to increase from 1.66 million in 1990 to 6.26 million in 2050 (1). Moreover, given the rapid aging of the population in Asian countries, epidemiological studies show that the incidence rate of HF in Asian countries is expected to increase further (2). A survey conducted in China shows that the incidence rate of $\mathrm{HF}$ accounted for $23.79 \%$ of all fractures in older adults (3). $\mathrm{HF}$ is the main health problem of older adults. Despite progress in anesthesia, surgical technology, and nursing, the 1 -year mortality from HF is still between $14 \%$ and $36 \%(4,5)$. Studies have shown that patients with postoperative complications have a threefold increase in 1 -year mortality compared with patients without complications. Delayed surgery for HF in the elderly is considered to be the main cause of increased mortality (6), delayed surgery may lead to increased complications and mortality, as well as prolonged hospital stay (7). Higher Charlson comorbidity index (CCI) and having more comorbidities is the strongest risk factor for complications (8). Postoperative urinary retention (POUR) is a common complication of HF patients, with an average prevalence of between $11 \%$ and $56 \%$ (9-12). Most elderly patients with HF have experienced POUR caused by immobility, severe pain related to fracture and surgery, and subsequent contraction of the internal sphincter of the bladder (13). Most POUR episodes are asymptomatic and are often underdiagnosed (14). However, POUR can also lead to adverse events, such as urinary tract infection or delirium, which can prolong hospital stays (14) and affect the recovery of activity levels (10). Although surgery can relieve the pain of the affected limb, correct joint deformity and improve the functional state of the affected limb (15), due to the decline of the physiological function of older patients, the process of postoperative functional recovery is relatively slow, which exerts considerable psychological pressure on patients. Self-efficacy is defined as the belief people have that they can perform the behaviors necessary to achieve their goals, which determines how individuals feel and think and facilitates their beliefs and behaviors (16). Self-efficacy plays a key role in disease treatment and rehabilitation (16-18). Studies have confirmed that self-efficacy plays a key role in postoperative functional recovery in patients with
$\operatorname{HF}(17,18)$ and is also associated with the decline of healthrelated quality of life in older patients with fractures (19). Resilience is the ability to respond effectively and actively adapt to the environment when individuals face adversity, trauma, or different forms of pressure. It is a positive psychological quality of individuals (20). Studies have shown that people with good resilience also have positive coping styles and healthy psychological states, and their quality of life is also higher (21).

To date, self-efficacy, resilience, and quality of life of older adults after HF combined with POUR have not been assessed. Therefore, this study aims to assess in older patients the effects of POUR after HF surgery on selfefficacy, resilience, and quality of life, with the aim of improving rehabilitation plans for HF patients. We present the following article in accordance with the STROBE reporting checklist (available at https://dx.doi.org/10.21037/ apm-21-2556).

\section{Methods}

\section{Research subjects}

A retrospective case-control study was conducted to study 469 older patients with HF, who underwent artificial hip replacement, cannulated screw internal fixation, steel plate internal fixation, and intramedullary nail internal fixation for the first time in the Department of Orthopedics, Xishan People's Hospital from June 2018 to June 2021. Inclusion criteria were: (I) age $\geq 60$ years old, (II) complete medical records, and (III) able to undergo follow-up investigations. Exclusion criteria were: (I) patients with original urinary diseases, (II) suffering from serious life-threatening complications such as heart, brain, or kidney failure, (III) patients with end-stage disease or expected survival less than 1 year, (IV) persons with cognitive and speech impairment, and $(\mathrm{V})$ patients had mental or psychological problems or low self-efficacy in the past. The study was conducted in accordance with the Declaration of Helsinki (as revised in 2013). The study was approved by the Ethics Committee of Xishan People's Hospital (2018115). Informed consent was taken from all the patients.

All variables were balanced according to propensity score matching (PSM). After excluding unmatched patients, 221 patients with HF were included in this study. They were grouped based on whether POUR had occurred after the operation, and accordingly 111 patients were in the POUR group (Group A), and the remaining 110 patients were in the non-POUR group (Group B) (see Figure 1). 


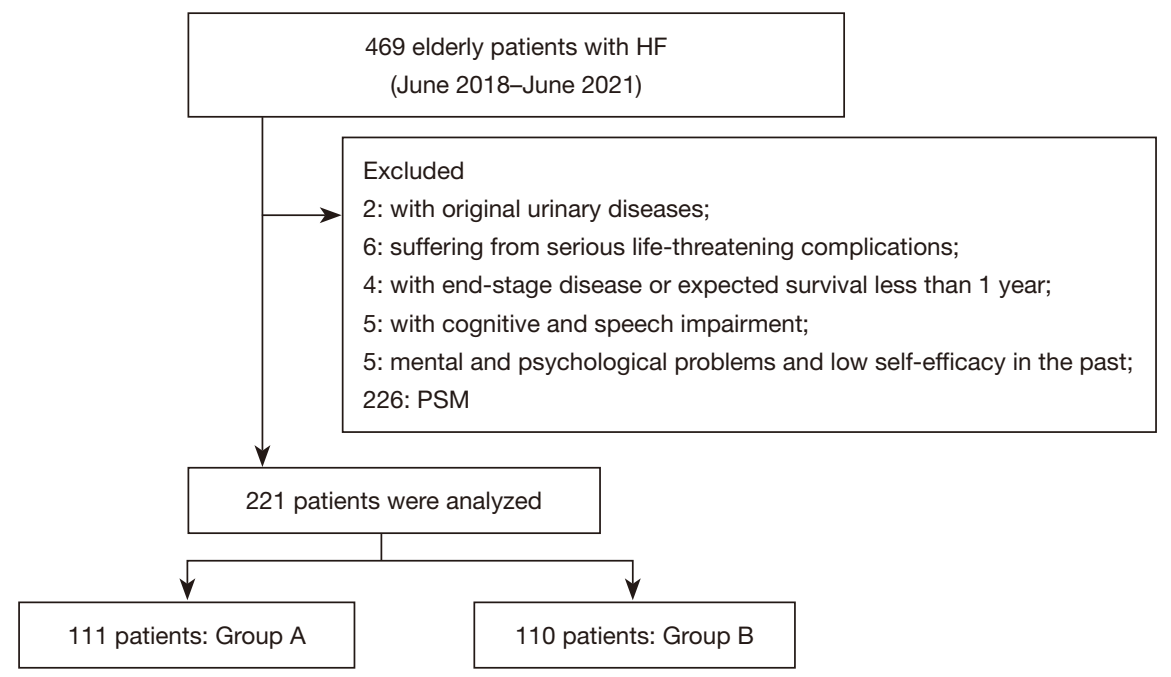

Figure 1 Study flowchart. HF, hip fracture; PSM, propensity score matching.

\section{Investigation method}

This study was approved by the ethics committee of our hospital. All researchers were trained by the investigators. The survey was administered 3 months after the operation. When the patient returned to the hospital for the review of the frontal and lateral films of the hip joint, a questionnaire was administered. First, the purpose, significance, and methodology of this study were introduced to the patient. Informed consent was obtained for completion of the survey. For those who could not complete the questionnaire by themselves, the investigators read the survey questions to participants and completed the questionnaire on behalf of the subjects after confirming their understanding and answers. The questionnaires were completed anonymously. After checking that there were no missing responses, the questionnaires were stored securely.

\section{Assessment instrument}

\section{Sociodemographic characteristics}

Gender, age, marital status, education level, average monthly income, type of medical expenses, family relationship, and history of other diseases were assessed.

\section{General self-efficacy scale (GSES)}

The scale was first developed in 1981 by Schwarzer (22), a clinical and health psychologists in Germany, and the Chinese version was translated and revised by Wang et al. (23). It measures one dimension and has 10 items. Using 4-point Likert scales, the score range is 10 to
40 points. The higher the total score, the greater is selfefficacy. The scale has high reliability and validity, and the Cronbach's $\alpha$ coefficient is 0.89 (24).

\section{Connor-Davidson Resilience Scale (CD-RISC)}

This scale was developed by foreign scholars Connor and Davidson (25) in 2003 to measure the positive psychological characteristics that help individuals adapt to adversities such as diseases and adverse events. Chinese scholars $\mathrm{Yu}$ and Zhang (26) translated it into Chinese, with a Cronbach $\alpha$ coefficient of 0.91 , measuring the three dimensions of toughness, self-improvement and optimism. It has 25 items, uses 5 -point Likert scales, and the score range is 0 to 100 points. The higher the total score, the greater the resilience.

\section{Medical outcomes study 36-item Short-Form Health Survey (SF-36) (27)}

The questionnaire includes eight dimensions: physical functioning (PF), role-physical (RP), bodily pain (BP), general health $(\mathrm{GH})$, vitality $(\mathrm{VT})$, social functioning (SF), roleemotional (RE), and mental health (MH). The scale provides a comprehensive overview of the quality of life of respondents based on the above eight aspects. The scores of all indicators are on a scale of $0-100$ points, and the score directly reflects the health status. The higher the score, the better the patient's health and the higher the health-related quality of life.

\section{Statistical analysis}

After sorting and numbering the questionnaires, the data 
Table 1 Baseline characteristics of the participants in both groups

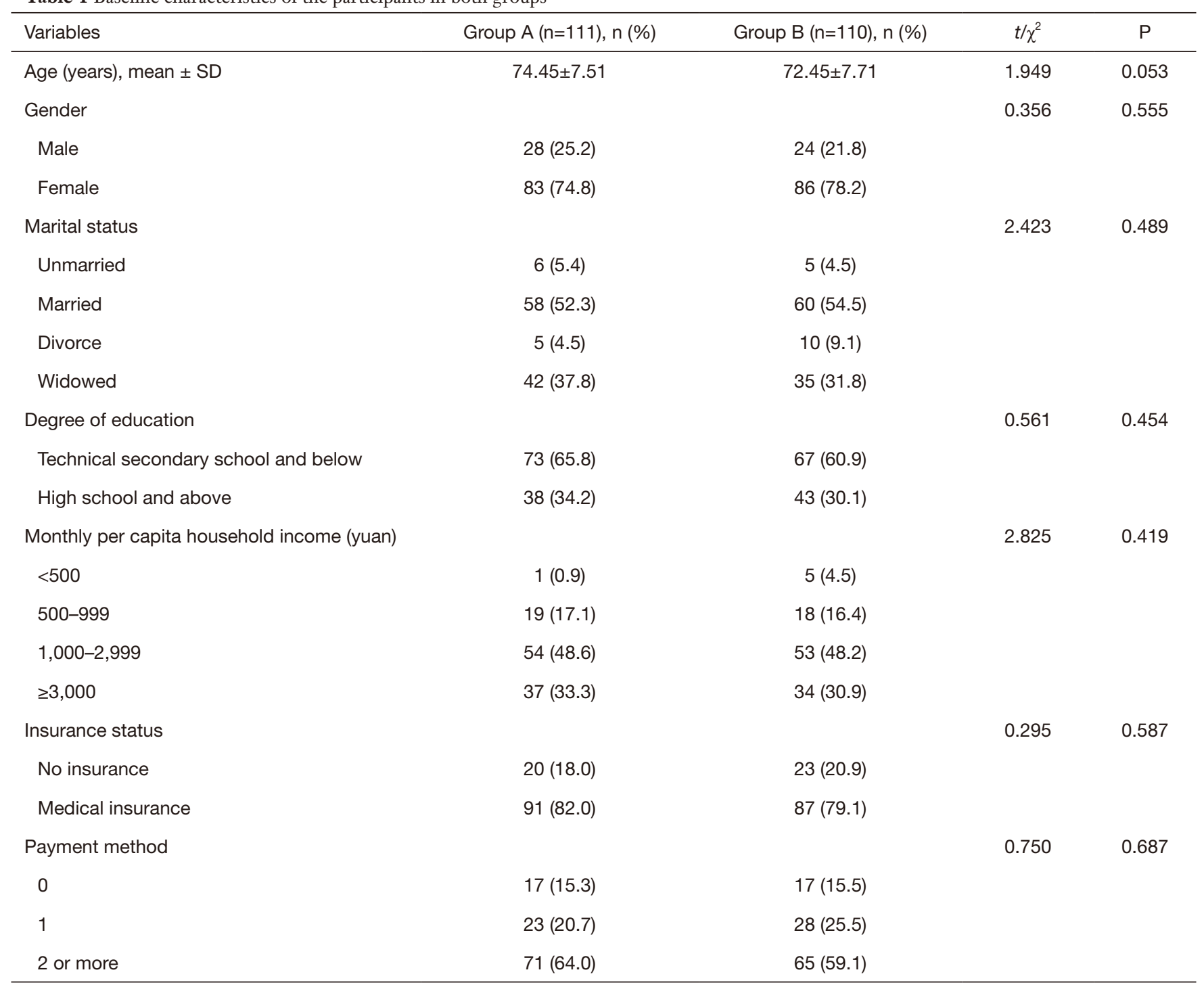

were entered into the statistical database. The Statistical Program for the Social Sciences version 22.0 (SPSS Inc., Chicago, IL, USA) software was used for statistical analysis. Measurement data with a normal distribution were described by $\bar{x} \pm s$, and categorical data were described as frequencies and percentages. The $t$-test for independent samples was used for comparisons between groups. The chi-square test was used for comparisons of frequency data between groups. Pearson's correlation coefficients were used to analyze the correlation between patients' selfefficacy, resilience, and quality of life. A $\mathrm{P}$ value $<0.05$ was considered as indicating statistical significance.

\section{Results}

\section{Basic patient characteristics}

A total of 469 older patients with HF were included. To further reduce selection bias, 469 patients were matched at a ratio of 1:1 using PSM to balance all baseline characteristics. Finally, 221 patients were included in this study, of which 111 were in the POUR group (Group A) and the remaining 110 patients were in the non-POUR group (Group B). There were no significant differences in the general data between the two groups $(\mathrm{P}>0.05)$. See Table 1. 


\section{Self-efficacy}

The self-efficacy score of Group A $(23.52 \pm 3.18)$ was lower than that of Group B $(27.23 \pm 2.40)$, and this difference was statistically significant $(\mathrm{P}<0.05)$. See Table 2 .

\section{Resilience}

Except for self-improvement, the scores and total scores of all dimensions of resilience of Group A were lower than those of Group B, and these differences were statistically significant $(\mathrm{P}<0.05)$. See Table 3.

\section{Quality of life}

The scores of all dimensions of the quality of life of Group A were lower than those of Group B, and these differences were statistically significant except for $\mathrm{RE}(\mathrm{P}<0.05)$. See Table 4 .

Table 2 Comparison of self-efficacy scores between the two groups $(\bar{x} \pm \mathrm{S})$

\begin{tabular}{lcc}
\hline Items & $\mathrm{N}$ & Self-efficacy \\
\hline Group A & 111 & $23.52 \pm 3.18$ \\
Group B & 110 & $27.23 \pm 2.40$ \\
$t$ & & 9.772 \\
$\mathrm{P}$ & & 0.000 \\
\hline
\end{tabular}

Correlation analysis of self-efficacy, resilience, and quality of life

The correlation analysis between self-efficacy and resilience in older patients with $\mathrm{HF}$ after the operation showed that self-efficacy was positively correlated with the total resilience score, and the toughness and optimism dimensions $(\mathrm{P}<0.01)$. The correlation analysis between selfefficacy and quality of life showed that self-efficacy was positively correlated with RP, BP, GH, VT, and $\mathrm{SF}(\mathrm{P}<0.01)$. Correlation analysis between resilience and quality of life showed that the total resilience score, and toughness and optimism dimensions were positively correlated with $\mathrm{PF}$, RP, BP, GH, VT, and SF $(\mathrm{P}<0.05)$. See Table 5.

\section{Discussion}

Incision pain after HF surgery or fear of urethral orifice pain during urination may cause high levels of mental tension, thus inhibiting parasympathetic nerves, increasing proneness to bladder sphincter reflex spasm and obstructing the drainage of urine, especially in the bladder of patients receiving anesthesia and those with postoperative analgesic pumps. The excitability of the parasympathetic nerve is reduced, and the sacral nerve that innervates the bladder is blocked and the recovery is delayed, which reduces the sensitivity of the patient to bladder filling. In addition, the patient is not used to urinating in bed, and clinically POUR

Table 3 Comparison of resilience scores between the two groups $(\bar{x} \pm \mathrm{S})$

\begin{tabular}{lccccc}
\hline Items & $\mathrm{N}$ & Total score & Toughness & Self-reliance & Optimistic \\
\hline Group A & 111 & $47.17 \pm 7.17$ & $25.13 \pm 5.70$ & $16.30 \pm 4.06$ & $5.75 \pm 1.53$ \\
Group B & 110 & $56.15 \pm 6.20$ & $29.67 \pm 4.23$ & $17.07 \pm 3.04$ & $9.41 \pm 2.73$ \\
$t$ & & 9.960 & 6.731 & 1.605 & 12.315 \\
$\mathrm{P}$ & & 0.000 & 0.000 & 0.110 & 0.000 \\
\hline
\end{tabular}

Table 4 Comparison of quality of life scores between the two groups $(\bar{x} \pm \mathrm{S})$

\begin{tabular}{lccccccccc}
\hline Item & $\mathrm{N}$ & $\mathrm{PF}$ & $\mathrm{RP}$ & $\mathrm{BP}$ & $\mathrm{GH}$ & $\mathrm{VT}$ & $\mathrm{SF}$ & $\mathrm{RE}$ & $\mathrm{MH}$ \\
\hline Group A & 111 & $60.78 \pm 15.62$ & $57.23 \pm 12.57$ & $49.38 \pm 14.74$ & $53.77 \pm 15.55$ & $58.05 \pm 10.90$ & $59.17 \pm 13.83$ & $68.58 \pm 7.64$ & $63.41 \pm 12.02$ \\
Group B & 110 & $69.25 \pm 9.33$ & $72.16 \pm 7.57$ & $69.53 \pm 7.47$ & $64.77 \pm 13.03$ & $66.95 \pm 9.89$ & $71.82 \pm 10.94$ & $69.36 \pm 8.24$ & $66.99 \pm 11.90$ \\
$t$ & & 4.881 & 10.685 & 12.804 & 5.698 & 6.357 & 7.536 & 1.672 & 2.228 \\
$\mathrm{P}$ & & 0.000 & 0.000 & 0.000 & 0.000 & 0.000 & 0.000 & 0.096 & 0.027 \\
\hline
\end{tabular}

PF, physical functioning; RP, role-physical; BP, bodily pain; $\mathrm{GH}$, general health; VT, vitality; SF, social functioning; RE, role-emotional; MH, mental health. 
Table 5 Correlation analysis of self-efficacy, resilience and quality of life ( $\mathrm{n}=221)$

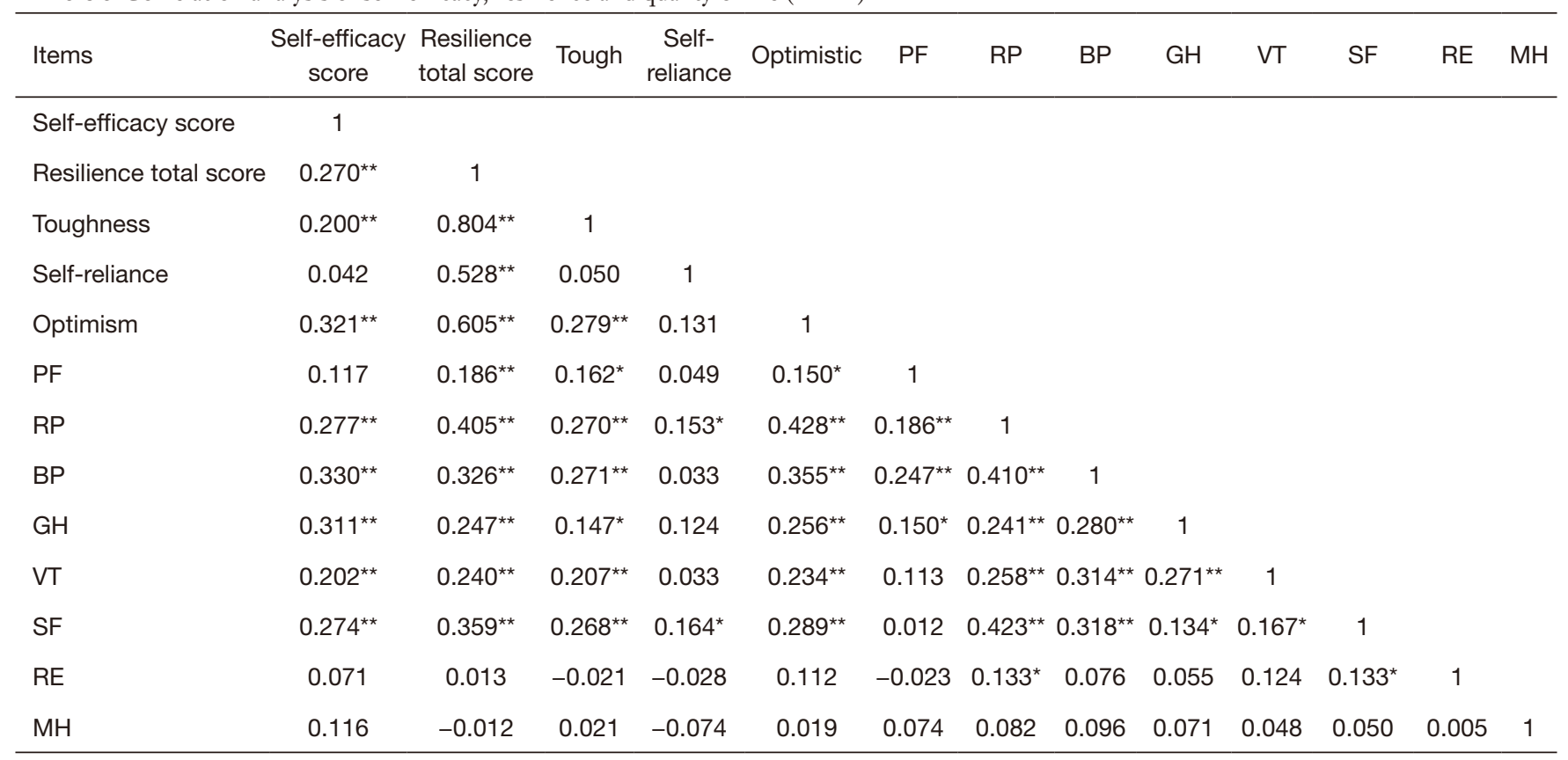

${ }^{*}, \mathrm{P}<0.05 ;{ }^{* *}, \mathrm{P}<0.01$. PF, physical functioning; RP, role-physical; BP, bodily pain; GH, general health; VT, vitality; SF, social functioning; RE, role-emotional; $\mathrm{MH}$, mental health.

is more likely to occur in the case of long-term indwelling catheters. Changes in urination patterns increase physical function and psychological distress in HF patients and affect patients' quality of life.

In the past, the evaluation of the treatment effect was mostly based on the recovery from postoperative trauma and the degree of recovery of physical function. The treatment effect has never previously been evaluated based on a comprehensive assessment of a patient's physiology and psychosocial characteristics. Self-efficacy is an important predictor of the physical and mental health of survivors following adversity. Improving the self-efficacy of patients can enhance their self-care ability, reduce patients' negative emotions, increase cure rates, and improve patients' quality of life (28). Self-efficacy does not depend on personal motivations. The implementation of healthy behaviors requires basic health knowledge and motivation that guides the process of self-regulation. Psychological resilience is the process of individuals adapting well to trauma, adversity, tragedy, or threats, that is, the individual's ability to rebound from difficult life events (29).

The results of this survey show that patients with POUR after HF have a lower level of psychological resilience than those without POUR, which requires the attention of medical staff. The patient's physical mobility is limited after a fracture, which can easily lead to severe psychological distress in patients. Studies have confirmed that the incidence of distress in patients following trauma recovery is high, and that low levels of psychological resilience are an important predictor of post-traumatic stress disorder. These studies show that improving the level of resilience plays a key role in the physical and mental rehabilitation of patients. The quality of life of patients with HF complicated with POUR 3 months after the operation was poor, and their quality-of-life scores on all dimensions were low. Following the operation, patients' physical and psychosocial quality-of-life scores showed that they had not adapted well. This may be because patients' poor postoperative PF directly affects their quality of life (30).

According to Bandura's self-efficacy theory, personal self-efficacy expectations depend on four main sources of information, namely alternative experience, oral persuasion, performance achievement, and physiological state, all of which can help patients to achieve higher self-efficacy (31). Studies have shown that high levels of psychological resilience can alleviate low mood in patients, increase their confidence and hope regarding their condition, and to a certain extent improve quality of life (32). Medical staff should implement targeted nursing intervention measures to enhance patients' resilience, mobilize patients' positive 
psychological potential, enhance patients' confidence in treatment, and provide necessary social support, and at the same time formulate detailed rehabilitation training plans and dietary guidance to improve the quality of life of patients. Nursing staff should support individuals affected psychologically by postoperative trauma, offer targeted group psychological counseling, give mental health lectures, and also conduct personalized interviews with patients for emotional management. Cognitive interventions, mental health information brochures, and creating an atmosphere of mutual encouragement may stimulate the patient's psychological potential, increase resilience, minimize the negative impact of trauma on the individual, and improve the patient's adaptation. Interventions should aim to relieve the patient's negative emotions and painful symptoms, allow the patient to deal with any postoperative trauma and restore physical and mental health.

\section{Conclusions}

The combination of POUR after HF significantly reduces the self-efficacy, mental resilience, and quality of life of older adults. Medical staff should focus on enhancing patients' self-confidence in overcoming their condition and restoring health, help patients to actively cope, enhance patients' psychological adjustment, and build psychological resilience of patients who have been traumatized postoperatively. Interventions should aim to reduce patients' psychological distress and promote their speedy recovery. This study cohort was relatively small, and the study only assessed the status of patients 3 months after the operation, without longer follow up. Future in-depth studies involving larger multicenter cohorts are warranted to further confirm these results.

\section{Acknowledgments}

Funding: This work was supported by the Wuxi Science and Technology Development Fund Project (WX18IIAN042).

\section{Footnote}

Reporting Checklist: The authors have completed the STROBE reporting checklist. Available at https://dx.doi. org/10.21037/apm-21-2556

Data Sharing Statement: Available at https://dx.doi. org/10.21037/apm-21-2556
Conflicts of Interest: All authors have completed the ICMJE uniform disclosure form (available at https://dx.doi. org/10.21037/apm-21-2556). The authors have no conflicts of interest to declare.

Ethical Statement: The authors are accountable for all aspects of the work in ensuring that questions related to the accuracy or integrity of any part of the work are appropriately investigated and resolved. The study was conducted in accordance with the Declaration of Helsinki (as revised in 2013). The study was approved by the Ethics Committee of Xishan People's Hospital (2018115). Informed consent was taken from all the patients.

Open Access Statement: This is an Open Access article distributed in accordance with the Creative Commons Attribution-NonCommercial-NoDerivs 4.0 International License (CC BY-NC-ND 4.0), which permits the noncommercial replication and distribution of the article with the strict proviso that no changes or edits are made and the original work is properly cited (including links to both the formal publication through the relevant DOI and the license). See: https://creativecommons.org/licenses/by-nc-nd/4.0/.

\section{References}

1. Cooper C, Campion G, Melton LJ 3rd. Hip fractures in the elderly: a world-wide projection. Osteoporos Int 1992;2:285-9.

2. Lau EM, Cooper C. The epidemiology of osteoporosis. The oriental perspective in a world context. Clin Orthop Relat Res 1996;(323):65-74.

3. Li X, Deng Y, Liu Z, et al. The epidemiology of hip fractures of the elderly in China. Journal of Practical Orthopaedics 2021;27:601-6.

4. Aharonoff GB, Koval KJ, Skovron ML, et al. Hip fractures in the elderly: predictors of one year mortality. J Orthop Trauma 1997;11:162-5.

5. Lawrence VA, Hilsenbeck SG, Noveck H, et al. Medical complications and outcomes after hip fracture repair. Arch Intern Med 2002;162:2053-7.

6. Brox WT, Roberts KC, Taksali S, et al. The American Academy of Orthopaedic Surgeons Evidence-Based Guideline on Management of Hip Fractures in the Elderly. J Bone Joint Surg Am 2015;97:1196-9.

7. Siegmeth AW, Gurusamy K, Parker MJ. Delay to surgery prolongs hospital stay in patients with fractures of the proximal femur. J Bone Joint Surg Br 2005;87:1123-6. 
8. Belmont PJ Jr, Garcia EJ, Romano D, et al. Risk factors for complications and in-hospital mortality following hip fractures: a study using the National Trauma Data Bank. Arch Orthop Trauma Surg 2014;134:597-604.

9. Tobu S, Noguchi M, Hashikawa T, et al. Risk factors of postoperative urinary retention after hip surgery for femoral neck fracture in elderly women. Geriatr Gerontol Int 2014;14:636-9.

10. Adunsky A, Nenaydenko O, Koren-Morag N, et al. Perioperative urinary retention, short-term functional outcome and mortality rates of elderly hip fracture patients. Geriatr Gerontol Int 2015;15:65-71.

11. Cialic R, Shvedov V, Lerman Y. Risk factors for urinary retention following surgical repair of hip fracture in female patients. Geriatr Orthop Surg Rehabil 2017;8:39-43.

12. Serrano Falcón B, Barceló López M, Mateos Muñoz B, et al. Fecal impaction: a systematic review of its medical complications. BMC Geriatr 2016;16:4.

13. Lovick TA. Central control of visceral pain and urinary tract function. Auton Neurosci 2016;200:35-42.

14. Boddaert J, Cohen-Bittan J, Khiami F, et al. Postoperative admission to a dedicated geriatric unit decreases mortality in elderly patients with hip fracture. PLoS One 2014;9:e83795.

15. Qiu G. Treatment strategies of osteoporotic fractures in the elderly. Chinese Journal of Geriatric Orthopaedics and Rehbilitation (Electronic Edition) 2015;(1):1-5.

16. Lind J, Mahler M. A systematic mixed methods review: Recovering from a hip fracture in a health promoting perspective. Nurs Open 2019;6:313-29.

17. Björk M, Niklasson J, Westerdahl E, et al. Self-efficacy corresponds to wrist function after combined plating of distal radius fractures. J Hand Ther 2020;33:314-9.

18. Auais M, Al-Zoubi F, Matheson A, et al. Understanding the role of social factors in recovery after hip fractures: a structured scoping review. Health Soc Care Community 2019;27:1375-87.

19. Grahn Kronhed AC, Enthoven P, Spångeus A, et al. Mindfulness and modified medical yoga as intervention in older women with osteoporotic vertebral fracture. J Altern Complement Med 2020;26:610-9.

20. Li L, Xie G. The psychosocial and biological mechanism of resilience. Medicine \& Philosophy 2012;33:32-3, 36.

21. Wagnild GM, Young HM. Development and psychometric evaluation of the Resilience Scale. J Nurs Meas 1993;1:165-78.

22. Schwarzer R. Optimistic self-beliefs: Assessment of general perceived self-efficacy in thirteen cultures. World Psychology 1997;3:177-90.

23. Wang C, Hu Z, Liu Y. Evidences for reliability and validity of the Chinese Version of General Self-Efficacy Scale. Chinese Journal of Applied Psychology 2001;7:37-40.

24. Wu Y, Xu D, Li Y, et al. Effect of family intervention on the depressed outpatients. Journal of Nursing Administration 2016;16:746-8.

25. Connor KM, Davidson JR. Development of a new resilience scale: the Connor-Davidson Resilience Scale (CD-RISC). Depress Anxiety 2003;18:76-82.

26. Yu X, Zhang J. A comparison between the Chinese Version of Ego-Resiliency Scale and Connor-Davidson Resilience Scale. Psychological Science 2007;30:1169-71.

27. Newnham EA, Harwood KE, Page AC. Evaluating the clinical significance of responses by psychiatric inpatients to the mental health subscales of the SF-36. J Affect Disord 2007;98:91-7.

28. Suri P, Rainville J, Gellhorn A. Predictors of patientreported recovery from motor or sensory deficits two years after acute symptomatic lumbar disk herniation. PM R 2012;4:936-44.e1.

29. Joyce S, Shand F, Tighe J, et al. Road to resilience: a systematic review and meta-analysis of resilience training programmes and interventions. BMJ Open 2018;8:e017858.

30. Dubljanin-Raspopović E, Marković-Denić L, Marinković $\mathrm{J}$, et al. Does early functional outcome predict 1-year mortality in elderly patients with hip fracture? Clin Orthop Relat Res 2013;471:2703-10.

31. Jing D, Jia L. Assessment of patients' psychological state and self-efficacy associated with postoperative constipation after thoracolumbar fracture surgery. J Int Med Res 2019;47:4215-24.

32. Li H, Zhang L, Zhang H, et al. Study on the relationship between resilience and the quality of life in patients with chronic hepatitis B. Chinese Journal of General Practice 2015;13:1278-9, 1359.

(English Language Editor: B. Meiser)

Cite this article as: Tang $\mathrm{Y}, \mathrm{Wu} \mathrm{XY}$, Tang $\mathrm{LJ}, \mathrm{Xu} \mathrm{N}, \mathrm{Ni} \mathrm{YJ}$ Effect of postoperative urinary retention in older patients with hip fracture on self-efficacy, resilience, and quality of life. Ann Palliat Med 2021;10(10):10789-10796. doi: 10.21037/apm-21-2556 